\title{
Fullminant COVID-19-Associated Myocarditis in an Otherwise Healthy Female
}

\author{
Gabriela C. Milla-Godoy ${ }^{1}$, Robin Park ${ }^{1}$, Weizheng Jiang ${ }^{1}$, Martin W. Hartkopf ${ }^{1}$, Thomas Treadwell ${ }^{2}$ \\ 1. Internal Medicine, MetroWest Medical Center, Tufts University School of Medicine, Framingham, USA 2. Infectious \\ Disease, MetroWest Medical Center, Tufts University School of Medicine, Framingham, USA
}

Corresponding author: Gabriela C. Milla-Godoy, gabrielamillag@gmail.com

\begin{abstract}
An outbreak of a severe respiratory illness caused by a novel coronavirus that began in China in late 2019 has become a pandemic. We report the case of COVID-19-associated myocarditis in a 45-year-old healthy female who presented with solely gastrointestinal symptoms. Initial investigations revealed ST-segment elevations in her electrocardiogram (EKG), elevated troponin levels, and a positive severe acute respiratory syndrome coronavirus 2 (SARS-Cov-2) reverse transcription-polymerase chain reaction (RT-PCR). Subsequently, she had rapid deterioration with the development of cardiogenic shock within hours of admission to a community hospital in Massachusetts. This case highlights an atypical presentation of COVID-19 with a fulminant course in this emerging and evolving disease.
\end{abstract}

Categories: Cardiology, Internal Medicine, Infectious Disease

Keywords: fulminant myocarditis, cardiac troponin, coronavirus disease 2019 (covid-19)

\section{Introduction}

In December 2019, an outbreak of pneumonia caused by severe acute respiratory syndrome coronavirus 2 (SARS-CoV-2) was first identified in a seafood market in Wuhan, China [1]. Subsequently, coronavirus disease 2019 (COVID-19) spread to multiple countries and was declared a pandemic by the World Health Organization in March 2020 [2]. Currently, as of December 30, 2020, there have been 19,432,125 infections in the United States [3] and 352,558 in the state of Massachusetts [4].

The virus mainly causes lung injury. However, multiple other manifestations have been described, including cardiovascular injury and coagulopathy, where the mechanisms have yet to be determined [5]. We present a rare case of an otherwise healthy female patient who presented with gastrointestinal disturbances, STsegment elevations, and then the development of fulminant myocarditis.

This article was previously presented as a clinical vignette abstract electronic poster presentation for the American College of Physicians, Massachusetts Chapter Meeting on Saturday, October 10, 2020.

Review began 01/07/2021 Review ended 01/11/2021 Published 01/16/2021

\section{๑) Copyright 2021}

Milla-Godoy et al. This is an open access article distributed under the terms of the Creative Commons Attribution License CC-BY 4.0., which permits unrestricted use, distribution, and reproduction in any medium, provided the original author and source are credited.

\section{Case Presentation}

A 45-year-old African female nursing assistant presented to the emergency department with four days of diarrhea, nausea, and vomiting. She endorsed recent contact with COVID-19-positive patients. She denied cough, shortness of breath, chest pain, and fever. She was a non-smoker and was not on any medications. Vital signs showed a blood pressure of $113 / 85 \mathrm{~mm} \mathrm{Hg}$, heart rate of 116 beats per minute (bpm), respiration of 18 breaths per minute, a temperature of 96.0 degrees Fahrenheit, and oxygen saturation of $98 \%$ on room air. Her examination was remarkable for an overweight, diaphoretic female in distress with abdominal tenderness and cold and clammy extremities.

An electrocardiogram (EKG) showed sinus tachycardia and diffuse ST-segment elevation in I, II, augmented Vector Left (aVL), and V3-V6 (Figure 1). 


\section{Cureus}

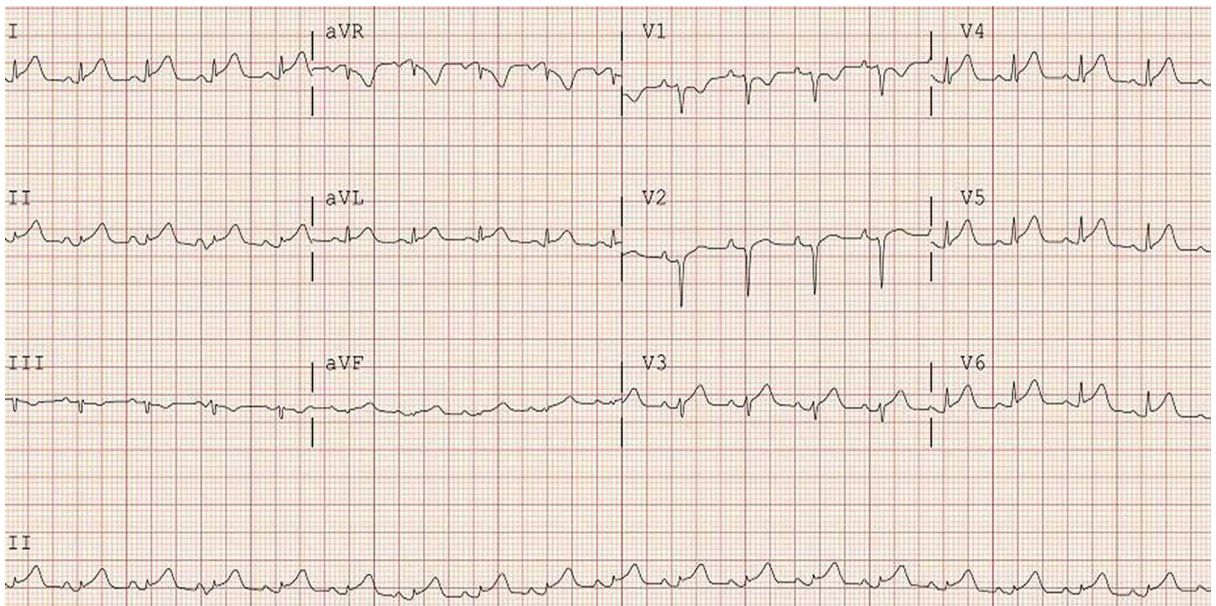

FIGURE 1: 12-lead electrocardiogram (EKG) showing diffuse STsegment elevations

Laboratory testing was remarkable for a white blood cell count of $3.810^{3} / \mathrm{uL}$ (reference range: 4.0 - 11.0 $10^{3} / \mathrm{uL}$ ), platelets $14410^{3} / \mathrm{uL}$, (reference range $150-40010^{3} / \mathrm{uL}$ ), international normalized ratio (INR) 1.26 (reference range 0.8 - 1.1), lactic acid $2.97 \mathrm{mmol} / \mathrm{L}$ (reference range: $0.5-2.00 \mathrm{mmol} / \mathrm{L}$ ), ferritin $562 \mathrm{ng} / \mathrm{mL}$ (reference range: 13 - $150 \mathrm{ng} / \mathrm{mL}$ ), C-reactive protein (CRP) $24.1 \mathrm{mg} / \mathrm{L}$, (reference range: 0 - $5 \mathrm{mg} / \mathrm{L}$ ); serum aspartate aminotransferase (AST) $141 \mathrm{U} / \mathrm{L}$ (reference range: 10 - $34 \mathrm{U} / \mathrm{L}$ ), lactate dehydrogenase (LDH) 464 U/L (reference range: 135 - $235 \mathrm{U} / \mathrm{L}$ ), creatine kinase (CK) $693 \mathrm{U} / \mathrm{L}$ (reference range: 26 - 192 U/L), Nterminal pro-B-type natriuretic peptide (NT-proBNP) $4,585 \mathrm{pg} / \mathrm{mL}$ (reference range: 0 - $450 \mathrm{pg} / \mathrm{mL}$ ), and troponin T $0.43 \mathrm{ng} / \mathrm{mL}$ (reference: 0 - 0.02). The chest $\mathrm{x}$-ray showed patchy infiltrates bilaterally (Figure 2). SARS-CoV-2 reverse transcription-polymerase chain reaction (RT-PCR) was positive.

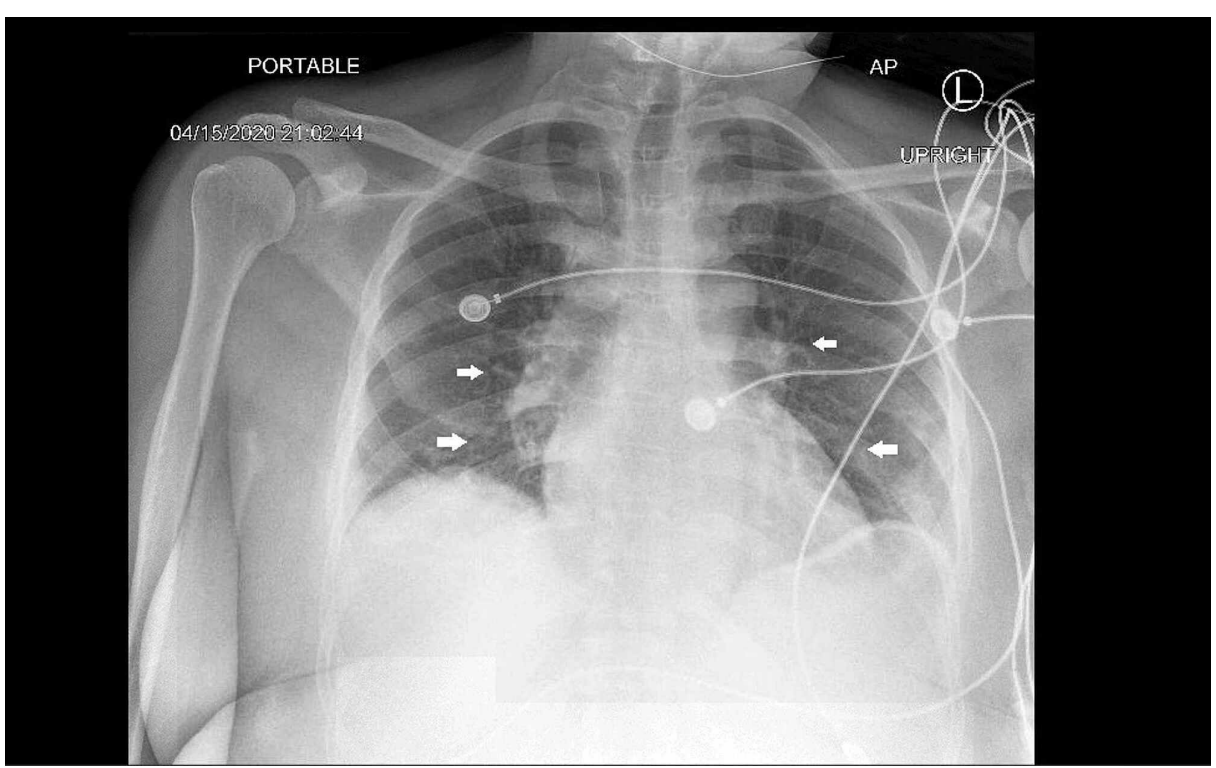

FIGURE 2: Chest x-ray showing patchy bilateral infiltrates (arrows)

The patient initially received 2 liters of normal saline, hydroxychloroquine $400 \mathrm{mg}$, aspirin $325 \mathrm{mg}$, and atorvastatin $80 \mathrm{mg}$ for presumptive COVID-19-associated myocarditis. She improved symptomatically and remained hemodynamically stable. Two hours later, she became lethargic with a heart rate of $130 \mathrm{bpm}$. Pulses were unmeasurable. She received another liter bolus of normal saline and was immediately transferred to the intensive care unit. A bedside echocardiogram showed a left ventricular ejection fraction of approximately $10 \%$ with global hypokinesis and no pericardial effusion.

Ultimately, the patient developed cardiogenic shock. She was intubated and started initially on norepinephrine and subsequently required additional pressor support with phenylephrine and dopamine. She received intravenous immunoglobulin and methylprednisolone. She subsequently became asystolic. She 
received four doses of intravenous (IV) epinephrine and 1 ampule of IV bicarbonate. The patient expired after 15 minutes of resuscitation.

\section{Discussion}

SARS-Cov-2 has caused significant morbidity and mortality worldwide. It is broadly known that the main target organ is the lung. However, recent case reports have reported cardiovascular involvement, including fulminant myocarditis [6-7]

Fulminant myocarditis is often preceded by a viral prodrome and characterized by sudden and severe diffuse cardiac inflammation. It is usually fatal, resulting from cardiogenic shock, arrhythmias, or multiorgan failure [8]. The proposed mechanisms of myocardial injury due to COVID-19 rely on the angiotensin-converting enzyme 2 (ACE2) receptor as its point of entry. Its inhibition may prevent the breaking and accumulation of angiotensin II, a proinflammatory factor in the lung, resulting in systemic inflammation, cytokine release, and procoagulant activity [9].

Fulminant myocarditis is a challenging diagnosis as its clinical presentation may overlap with pericarditis and acute coronary syndrome. Troponin elevation is a common finding. Although an elevated troponin level in a COVID-19 infection does not necessarily mean fulminant myocarditis, its high clinical significance relies on the fact that it has been shown that elevation of this marker is associated with higher mortality, even in those without underlying cardiovascular disease [10-11]. The most common EKG findings include ST-segment elevations and PR segment depression. Echocardiography findings may range from focal wall motion abnormalities to global hypokinesis with systolic dysfunction [12]. Currently, there are no established therapeutic agents for COVID-19 myocarditis, although some cases have reported therapeutic benefits associated with corticosteroids and immunoglobulin G [13-14].

This case, and many others with reported SARS-CoV-2 myocarditis, give insight into the importance of close monitoring in patients that present with elevated cardiac biomarkers as this may be an indicator for a poor prognosis.

\section{Conclusions}

Fulminant myocarditis may be a complication associated with COVID-19 infection. A mechanism of cardiac injury by SARS-CoV-2 has yet to be determined. One that has been proposed may be attributed to its inhibition of the ACE2 receptor as its point of entry, resulting in systemic inflammation and cytokine release. Elevated troponin T in COVID-19 infection may be a marker of higher mortality and poor prognosis. Regardless of the clinical presentation, close monitoring is paramount for the early recognition of severe complications. Further large-scale studies are needed in order to determine the role of intravenous immunoglobulin G (IVIG) and corticosteroid therapy on patients with COVID-19-associated myocarditis.

\section{Additional Information \\ Disclosures}

Human subjects: Consent was obtained or waived by all participants in this study. Conflicts of interest: In compliance with the ICMJE uniform disclosure form, all authors declare the following: Payment/services info: All authors have declared that no financial support was received from any organization for the submitted work. Financial relationships: All authors have declared that they have no financial relationships at present or within the previous three years with any organizations that might have an interest in the submitted work. Other relationships: All authors have declared that there are no other relationships or activities that could appear to have influenced the submitted work.

\section{References}

1. Zhu N, Zhang D, Wang W, et al.: A novel coronavirus from patients with pneumonia in China, 2019 . N Engl J Med. 2020, 382:727-33. 10.1056/NEJMoa2001017

2. WHO Director-General's opening remarks at the media briefing on COVID-19 - 11 March 2020 . (2020). Accessed: December 30, 2020: http://www.who.int/director-general/speeches/detail/who-director-generals-opening-remarks-at-the-media-briefing-on-c....

3. CDC COVID Data Tracker: Maps, charts, and data provided by the CDC . (2020). Accessed: December 30, 2020: http://covid.cdc.gov/covid-data-tracker/.

4. COVID-19 Response Reporting. (2020). Accessed: December 30, 2020: http://www.mass.gov/infodetails/covid-19-response-reporting.

5. Sawalha K, Abozenah M, Kadado AJ, et al.: Systematic review of COVID-19 related myocarditis: insights on management and outcome. Cardiovasc Revasc Med. 2020, (Epub ahead of print):10.1016/j.carrev.2020.08.028

6. Paul JF, Charles P, Richaud C, Caussin C, Diakov C: Myocarditis revealing COVID-19 infection in a young patient. Eur Heart J Cardiovasc Imaging. 2020, 21:776. 10.1093/ehjci/jeaa107

7. Irabien-Ortiz Á, Carreras-Mora J, Sionis A, Pàmies J, Montiel J, Tauron M: Fulminant myocarditis and COVID-19. Rev Esp Cardiol. 2020, 73:503-504. 10.1016/j.rec.2020.04.005

8. Veronese G, Ammirati E, Cipriani M, Frigerio M: Fulminant myocarditis: characteristics, treatment, and 


\section{Cureus}

outcomes. Anatol J Cardiol. 2018, 19:279-86. 10.14744/AnatolJCardiol.2017.8170

9. Long B, Brady WJ, Koyfman A, Gottlieb M: Cardiovascular complications in COVID-19. Am J Emerg Med. 2020, 38:1504-507. 10.1016/j.ajem.2020.04.048

10. Guo T, Fan Y, Chen M, et al.: Cardiovascular implications of fatal outcomes of patients with coronavirus disease 2019 (COVID-19). JAMA Cardiol. 2020, 305:811-18. 10.1001/jamacardio.2020.1017

11. Ruan Q, Yang K, Wang W, Jiang L, Song J: Clinical predictors of mortality due to COVID-19 based on an analysis of data of 150 patients from Wuhan, China. Intensive Care Med. 2020, 46:846-48. 10.1007/s00134020-05991-X

12. Siripanthong B, Nazarian S, Muser D, et al.: Recognizing COVID-19-related myocarditis: the possible pathophysiology and proposed guideline for diagnosis and management. Heart Rhythm. 2020, 17:1463-71. 10.1016/j.hrthm.2020.05.001

13. Zeng JH, Liu YX, Yuan J, et al.: First case of COVID-19 complicated with fulminant myocarditis: a case report and insights. Infection. 2020, 48:773-77. 10.1007/s15010-020-01424-5

14. Hu H, Ma F, Wei X, Fang Y: Coronavirus fulminant myocarditis treated with glucocorticoid and human immunoglobulin. Eur Heart J. 2020, ehaa190. 10.1093/eurheartj/ehaa190 